\section{Education Committee News}

Dr. Donald Goldmann, Chairman-Educational Activities Committee, reports that Dr. Allen Kaiser has been working closely with $\mathrm{Dr}$. James Hughes, Director, Hospital Infection Program, Centers for Disease Control (CDC), to develop a SHEA-CDC training program for new hospital epidemiologists and for infectious disease fellows interested in a career in infection control. These sessions will be held at regular intervals at the CDC and will replace the regional seminars sponsored by SHEA over the past few years. A draft curriculum is being prepared for circulation to members of the SHEA Educational Activities Committee.

Through the generosity of a grant from Glaxo, Inc., SHEA will sponsor a session entitled "Nosocomial Infections: Problems and Priorities" at the International Congress for Infectious Diseases in Rio de Janeiro, Brazil, A pril 17-21, 1988. Partial travel support has been awarded to Dr. Lee Ford-Jones, Dr. Nalini Rao, and Dr. Ferdinand Otaiza to present papers at this session.

As noted in a recent letter to SHEA members, Dr. Otaiza has invited a SHEA delegation to visit Chile after the Rio meeting. He has asked that the team include an adult ID specialist, a pediatric ID specialist, and a microbiologist. Dr. Otaiza has developed a superb infection control network in Chile, and this should be an exciting consultation. Interested SHEA members should contact Dr. Don Goldmann, Chairman, Educational Activities Committee, at the Division of Infectious Diseases, The Children's Hospital, 300 Longwood A ve., Boston, MA 02115 as soon as possible. Telephone (617) 735-7623.

Brief items of interest for the SHEA Newsletter may be sent to Robert A. Weinstein, MD, SHEA Newsletter Editor, Division of Infectious Diseases, Michael Reese Hospital, Lake Shore Drive at 31st St., Chicago, IL 60616. Copy must be typed, double-spaced, and may not exceed five pages. 